\title{
Efficient detection of the V600E mutation of the $B R A F$ gene in papillary thyroid carcinoma using multiplex allele-specific polymerase chain reaction combined with denaturing high-performance liquid chromatography
}

\author{
R.X. Gong ${ }^{1}$, Y.P. Gong ${ }^{1}$, J. Yang ${ }^{1}$, T. Wei ${ }^{1}$, J. Li-Ling ${ }^{2,3}$ and J.Q. Zhu ${ }^{1}$ \\ ${ }^{1}$ Department of Thyroid and Breast Surgery, West China Hospital, \\ Sichuan University, Chengdu, China \\ ${ }^{2}$ Laboratory of Disease Genomics and Bioinformatics, \\ State Key Laboratory of Biotherapy, Sichuan University, Chengdu, China \\ ${ }^{3}$ Sino-Dutch Biomedical and Information Engineering School, \\ Northeastern University, Shenyang, China
}

Corresponding author: J.Q. Zhu

E-mail: nc12000@126.com

Genet. Mol. Res. 12 (4): 4990-4997 (2013)

Received February 26, 2013

Accepted August 18, 2013

Published October 24, 2013

DOI http://dx.doi.org/10.4238/2013.October.24.11

\begin{abstract}
Mutations in the V-raf murine sarcoma viral oncogene homolog B1 gene $(B R A F)$ play an important role in the pathogenesis of papillary thyroid cancer (PTC). In this study, a $B R A F \mathrm{~V} 600 \mathrm{E}$ mutation was detected in formalin-fixed and paraffin-embedded PTC samples using multiplex allele-specific polymerase chain reaction and denaturing high-performance liquid chromatography. The sensitivity of the assays was validated in two cell lines, K1 and RO82-W-1, which were respectively positive and negative for the mutation. The method enabled detection of very low concentrations
\end{abstract}


( $\sim 1 \%)$ of the mutation, with positive findings obtained in 119 of the 187 samples $(63.6 \%)$. The mutation was not detected in 20 cases of benign thyroid diseases. The presence of the mutation was significantly associated with ages $>45$ years, the tumor-nodesmetastasis stage, region of metastasis, and clinical outcome $(\mathrm{P}<$ 0.05). Although no correlation was found between the mutation and lymph node metastasis, the proportions of patients carrying a mutation differed significantly between central and lateral cervical lymph node metastasis $(\mathrm{P}<0.05)$. Multivariate logistic regression analysis also indicated the presence of mutation, tumor size, and cervical lymph node metastasis to be independent predictors for recurrence and distant metastasis. We conclude that a high proportion of PTC cases likely harbors the BRAF V600E mutation. This mutation can be used as an independent factor for predicting the recurrence and distal metastasis of PTC tumors.

Key words: Denaturing high-performance liquid chromatography; $B R A F$ gene; Multiplex allele-specific PCR; Prognosis;

V600E mutation

\section{INTRODUCTION}

Papillary thyroid cancer (PTC) is a common endocrine tumor with increasing incidence in recent years in China. Clinically, the prognosis is good, with a 10-year survival rate reaching $90 \%$. However, some PTC cases are more aggressive, easier to relapse and metastasize, and can lead to death. Therefore, preoperative judgment and intervention measures are important (Ries et al., 2007). Various clinicopathological factors have been used for prognosis, which include age, gender, tumor size, histological type, interstitial fibrosis of the tumor, and thyroid infiltration. However, no consensus has yet been reached with respect to the most relevant and predictive factors (Schlumberger and Pacini, 2003; Witt, 2008).

Recently, mutations of the V-raf murine sarcoma viral oncogene homolog B1 gene $(B R A F)$ have been found to play an important role in the pathogenesis of thyroid cancer. In particular, the $B R A F \mathrm{~V} 600 \mathrm{E}$ mutation has been found in $28-83 \%$ of PTC cases. This mutation is rarely found in normal thyroid tissue or in benign types of thyroid diseases (Davies et al., 2002; Xing, 2005; Kebebew et al., 2007; DeLuca et al., 2008; Kim et al., 2012). Several studies have also found significant associations between the mutation with clinicopathological features such as patient age, extrathyroidal invasion, lymph node metastasis, and tumor stage, which may help clinical prognoses of PTC (Costa et al., 2008; Xing et al., 2009; Gong et al., 2009; Howell et al., 2011). Furthermore, a small molecule targeting a downstream kinase of $B R A F$ has also attracted attention recently (Bollag et al., 2012). In the present study, we detected the $B R A F$ V600E mutation in formalin-fixed and paraffin-embedded PTC samples using multiplex allele-specific polymerase chain reaction (PCR) and denaturing high-performance liquid chromatography (DHPLC). Associations between these results with respect to clinicopathological features of the patients were then evaluated. 


\section{MATERIAL AND METHODS}

\section{Patient data}

Clinical data and tissue samples were collected from 187 patients treated at West China Hospital, Sichuan University, between May 2009 and May 2011, for pathologically confirmed PTC. The control group comprised 20 patients with benign types of thyroid diseases. All cases were diagnosed by at least two pathologists using World Health Organization criteria. Tumornode-metastasis (TNM) staging of PTC cases were determined based on the standard released by the American Joint Committee on Cancer (AJCC). Two thyroid cancer cell lines, K1 and RO82-W-1, which were heterozygous and negative for the BRAF V600E mutation, respectively, were kindly provided by the Molecular Biology Laboratory of West China Hospital. All patients underwent total thyroidectomy + central area or functional cervical lymph node dissection performed by the same group of surgeons, which was followed by three weeks of routine $\left[{ }^{131} \mathrm{I}\right]$ therapy with doses ranging from 100 to $200 \mathrm{mCi}$. Five months after treatment, all patients were followed up with thyroid scans to confirm no residual glands. The patients were followed up for 2 years with measurement of serum thyroglobulin, $(>2 \mu \mathrm{g} / \mathrm{L})$, which was suggestive of recurrence/distant metastasis. The follow-up was completed in 176 cases and 11 cases were lost.

\section{Sample preparation}

All cases were anonymized with identifiers removed. Therefore, such samples were exempted from Institutional Review Board approval. Five-micrometer tissue sections were cut in a microtome (Leica RM2255 rotary microtome, Wetzlar, Germany) using low-profile steel blades. Deparaffinization was performed in fresh xylene solution for $7 \mathrm{~min}$, and this was repeated three times using staining trays with fresh solutions. The process was followed by prolonged washing and hydration in ethanol solutions: four times for 5 min using fresh $100 \%$ ethanol, two times for $5 \mathrm{~min}$ in fresh $95 \%$ ethanol, and a final step of $5 \mathrm{~min}$ in fresh $70 \%$ ethanol. Subsequently, the slides were transferred to distilled water. For each sample, the DNA from 10 slides was extracted with the TIANamp Genomic DNA Kit (Qiagen, Germany) according to manufacturer instructions. For reference cell lines, the DNA was extracted with a TIANGEN genomic DNA extraction kit (TIANGEN, China) according to manufacturer instructions. The quantity of the extracted DNA was measured with a NanoDrop ND-1000 Spectrophotometer.

For PCR, a specific primer for the BRAF V600E mutation was designed, which amplifies a fragment length of $126 \mathrm{bp}$, with its 3 '-end targeting a mismatch site. In addition, primers for the wild-type sequence were designed. The TBXAS1 gene was used as the internal control, whose primers amplified a 100-bp fragment, which could be distinguished from that of $B R A F$ gene amplicons. The primer sequences are listed in Table 1.

\begin{tabular}{llc}
\multicolumn{2}{l}{ Table 1. Primer sequences for multiplex allele-specific PCR. } & \\
\hline Gene & Primer sequence (5' $\left.\rightarrow 3^{\prime}\right)$ & Amplicon size (bp) \\
\hline BRAF mut & Forward: 5'-GGTGATTTTGGTCTAGCTACATA-3' & 126 \\
\multirow{2}{*}{ R $X A S 1$} & Reverse: 5'-GGCCAAAATTTAATCAGTGG-3' & 100 \\
BRAF seq & Forward: 5'-GCCCGACATTCTGCAAGTCC-3' & 269 \\
& Reverse: 5'-GGTGTTGCCGGGAAGGGTT-3' & 269 \\
\hline
\end{tabular}

$B R A F$ mut = BRAF V600E mutation; $B R A F$ seq = wild-type. 


\section{Mutation analysis}

Multiplex PCR amplification was carried out in a $25-\mu \mathrm{L}$ volume containing $30 \mathrm{ng}$ template DNA, 10 pmol BRAF gene primers, 5 pmol TBXAS1 gene primers, $0.1 \mathrm{M}$ dNTPs, and $1.5 \mathrm{U}$ Taq enzyme. PCR conditions were $95.0^{\circ} \mathrm{C}$ for $5 \mathrm{~min} ; 94.0^{\circ} \mathrm{C}$ for $30 \mathrm{~s}, 54.0^{\circ} \mathrm{C}$ for 30 $\mathrm{s}$, and $72^{\circ} \mathrm{C}$ for $30 \mathrm{~s}$ for $30 \mathrm{cycles}$; and $72^{\circ} \mathrm{C}$ for $10 \mathrm{~min}$. For $B R A F$ sequence amplification, the reaction was conducted in a $50-\mu \mathrm{L}$ volume containing $50 \mathrm{ng}$ template DNA, 10 pmol of each primer, $0.2 \mathrm{M}$ dNTPs, and $1.5 \mathrm{U}$ Taq enzyme. PCR conditions were $95.0^{\circ} \mathrm{C}$ for $5 \mathrm{~min} ; 94.0^{\circ} \mathrm{C}$ for $30 \mathrm{~s}, 54.0^{\circ} \mathrm{C}$ for $30 \mathrm{~s}$, and $72^{\circ} \mathrm{C}$ for $30 \mathrm{~s}$ for 40 cycles; and $72^{\circ} \mathrm{C}$ for $10 \mathrm{~min}$.

For DHPLC analysis, the PCR product was run through a DNASep ${ }^{\circledR}$ nucleic acid analysis column (Transgenomics, USA) and analyzed with a WAVE system under multi-fragment isolation mode. For distinguishing single fragments, the fragment size was set to $110 \mathrm{bp}$, the temperature was set to $50^{\circ} \mathrm{C}$, the flow rate was set to $0.9 \mathrm{~mL} / \mathrm{min}$, and the UV detection wavelength was set at $260 \mathrm{~nm}$. The results were analyzed with the Navigator software.

To validate the above assay, DNA was extracted respectively from K1 and RO82-W-1 cells and the concentration was adjusted to $30 \mathrm{ng} / \mu \mathrm{L}$. To validate the sensitivity of detection, DNA from RO82-W-1 cells, which contains the wild-type $B R A F$ gene, and that of $\mathrm{K} 1$, which contains the $B R A F$ V600E mutation, were mixed with various ratios, e.g., 1:1, 1:4; $1: 10 ; 1: 33.3$, and $1: 100$. Thirty nanograms mixed DNA was subjected to allele-specific PCR amplification and DHPLC analysis.

\section{Data analysis}

Statistical analyses were performed using the SPSS 13.0 software. Data for different groups were compared using the $\chi^{2}$ test. $\mathrm{P}<0.05$ was considered to be statistically significant. For multivariate logistic regression analysis, the observed $\mathrm{P}$ value, relative risk (odds ratio) and $95 \%$ confidence interval were calculated.

\section{RESULTS}

\section{Clinical data}

The 187 cases of PTC included 159 females and 28 males aged between 8 and 80 $(42.57 \pm 12.88)$ years. Based on TNM staging, 117 cases were at stage I, 2 cases were at stage II, 38 cases were at stage III, and 30 cases were at stage IV. There were 59 cases of bilateral PTC, 47 cases of left lobe PTC, 78 cases of right lobe PTC, and three cases of isthmus PTC. Of all patients, 176 completed the follow-up. Recurrence tumors were found in 59 cases (33.5\%).

\section{Validation of the sensitivity of multiplex allele-specific PCR combined with DHPLC assay}

Following multiplex allele-specific PCR, all samples were subjected to DHPLC analysis. Two eluting peaks were observed. The left elution peak represented the internal reference $T B X A S 1$ amplicon with a fragment size of $100 \mathrm{bp}$, and the right elution peak represented the mutant $B R A F$ mutation amplicon with a fragment size of $126 \mathrm{bp}$. As shown in Figure 1, the sensitivity of detection reached $1 \%$. Corresponding to reduction in mutation content, the right 
peaks gradually reduced. By contrast, the peaks representing the reference gene amplicon remained relatively stable, showing only two distinct types, i.e., 50 and $25 \%$.

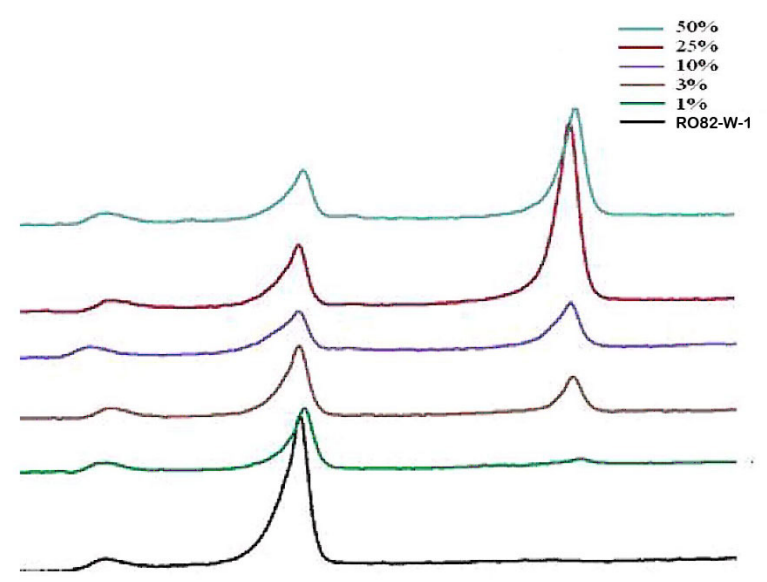

Figure 1. Sensitivity of multiplex allele-specific PCR and DHPLC for the detection of the BRAF V600E mutation. DNA extracted from K1 and RO82-W-1 cell lines were mixed with various ratios ranging from 1:1 to 100:1. Elution peaks on the left represent amplicons of the normal control, those on the right represent amplicons of samples containing various concentration of the $B R A F \mathrm{~V} 600 \mathrm{E}$ mutation.

\section{Detection of the $B R A F$ mutation}

The BRAF V600E mutation was detected in 119 of the 187 cases $(63.6 \%)$. As shown in Figure 2, for those with lower mutation-peaks in the DHPLC analysis, DNA sequencing only showed a very low peak for the mutation or even a normal result. No BRAF V600E mutation was detected in the control group comprising 20 cases of benign thyroid lesions.

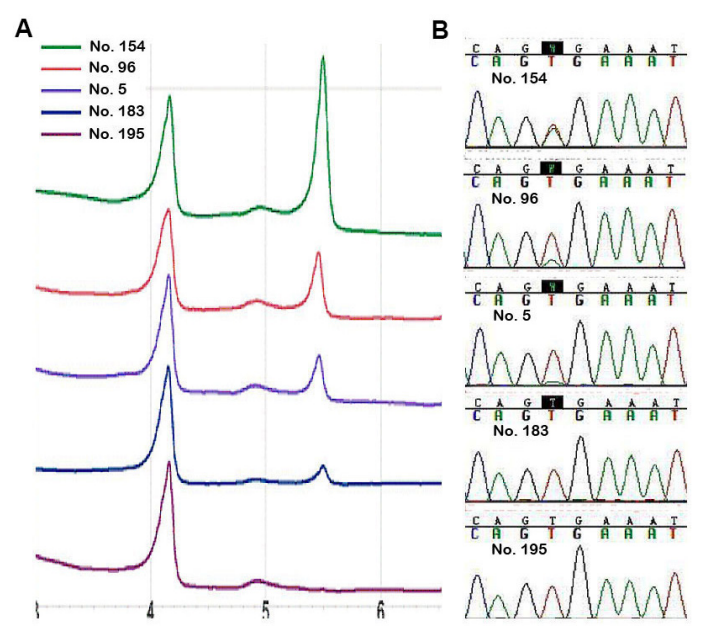

Figure 2. Detection of the BRAF V600E mutation. A. Results of multiplex allele-specific PCR and DHPLC. B. Results of DNA sequencing of the same samples. Although samples 5 and 183 have the mutation, on DNA sequencing the mutation peak for sample 5 was quite low, and no mutation peak for sample 183 could be seen. 


\section{Correlation between the $B R A F$ gene mutation and clinicopathological features of PTC}

Statistical analysis indicated that the $B R A F$ V600E mutation was closely related with age, tumor staging, and clinical prognosis $(\mathrm{P}<0.05)$, but not with gender, lymph node metastasis, tumor size, or site (Table 2). In addition, among patients with lymph node metastasis, the frequency of the BRAF V600E mutation differed significantly between those with central cervical lymph node metastasis $(75.3 \%)$ and with metastasis of lateral cervical lymph nodes $(49.3 \%)(\mathrm{P}<0.05)$.

\begin{tabular}{|c|c|c|c|c|}
\hline \multirow[t]{2}{*}{ Groups } & \multirow[t]{2}{*}{ No. of cases } & \multicolumn{2}{|c|}{$B R A F$ V600E mutation (\%) } & \multirow[t]{2}{*}{ P value } \\
\hline & & Positive & Negative & \\
\hline Gender & & & & 0.401 \\
\hline Male & 28 & 20 & 8 & \\
\hline Female & 159 & 99 & 60 & \\
\hline Age & & & & $0.002 *$ \\
\hline$\geq 45$ years & 75 & 58 & 17 & \\
\hline$<45$ years & 112 & 61 & 51 & \\
\hline Tumor size & & & & 0.279 \\
\hline$>2 \mathrm{~cm}$ & 144 & 95 & 49 & \\
\hline$\leq 2 \mathrm{~cm}$ & 43 & 24 & 19 & \\
\hline Lymph node metastasis & & & & 0.582 \\
\hline Yes & 146 & 91 & 55 & \\
\hline No & 41 & 28 & 13 & \\
\hline Region of metastasis & & & & $0.002 *$ \\
\hline Central & 73 & 55 & 18 & \\
\hline Lateral & 73 & 36 & 37 & \\
\hline TNM stage & & & & $0.003 *$ \\
\hline I-II & 119 & 66 & 53 & \\
\hline III-IV & 68 & 53 & 15 & \\
\hline Site of tumor & & & & 0.138 \\
\hline Bilateral & 59 & 33 & 26 & \\
\hline Unilateral & 125 & 85 & 40 & \\
\hline Isthmus & 3 & & & \\
\hline Location & & & & 0.698 \\
\hline Left lobe & 47 & 31 & 16 & \\
\hline Right lobe & 78 & 54 & 24 & \\
\hline Isthmus & 3 & & & \\
\hline Bilateral & 59 & & & \\
\hline Outcome & & & & $0.03^{*}$ \\
\hline Cure & 117 & 69 & 48 & \\
\hline Recurrence/metastasis & 59 & 45 & 14 & \\
\hline
\end{tabular}

$* \mathrm{P}<0.05$ for statistically significant differences $\left(\chi^{2}\right.$ test $)$.

Univariate analysis indicated that clinical prognosis was strongly correlated with tumor size, TMN stage, and the presence of the $B R A F$ V600E mutation $(\mathrm{P}<0.05)$, but not with gender, age, or lymph node metastasis. Multivariate regression analysis revealed that lymph node metastasis and the BRAF V600E mutation were independent factors for the prediction of prognosis (Table 3).

Table 3. Correlation between recurrence and distant metastasis and clinicopathological features of papillary thyroid cancer.

\begin{tabular}{|c|c|c|c|c|}
\hline & \multirow{2}{*}{$\begin{array}{c}\text { Univariable analysis } \\
\text { P value }\end{array}$} & \multicolumn{3}{|c|}{ Multivariable analysis } \\
\hline & & $\mathrm{P}$ value & OR & $95 \% \mathrm{CI}$ \\
\hline Gender & 0.119 & 0.134 & & \\
\hline Age (years) & 0.871 & 0.999 & & \\
\hline Tumor size & $0.004^{*}$ & 0.074 & 0.393 & $0.141-1.093$ \\
\hline Lymph node metastasis & $0.003^{*}$ & 0.044 & 0.333 & $0.114-0.973$ \\
\hline TNM staging & 0.406 & 0.999 & & \\
\hline$B R A F$ gene mutation & $0.030^{*}$ & $0.021^{*}$ & 2.471 & $1.149-5.312$ \\
\hline
\end{tabular}

$* \mathrm{P}<0.05$ for statistically significant differences $\left(\chi^{2}\right.$ test $)$. 


\section{DISCUSSION}

The occurrence and development of PTC involves multiple genetic abnormalities, among which the BRAF V600E mutation has been the most common, although the detection rate varies among different regions and with different methods (Davies et al., 2002; Xing, 2005; Kebebew et al., 2007; DeLuca et al., 2008; Kim et al., 2012). In the present study, 119 of the 187 cases $(63.6 \%)$ were found to harbor the mutation, which is in accordance with previous reports.

Although several studies have found that $B R A F$ gene mutations are closely correlated with thyroid cancer prognosis, few of these studies have come from China (Costa et al., 2008; Gong et al., 2009; Henderson et al., 2009; Xing et al., 2009; Howell et al., 2011). In the present study, we demonstrated that the $B R A F$ V600E mutation is closely related with age, tumor staging, and clinical prognosis. Recently, Alzahrani and Xing (2013) also found that $B R A F$ gene mutations in thyroid cancer could predict lymph node metastasis, which is consistent with our results. Furthermore, multivariate regression analysis also suggested that lymph node metastasis and the presence of $B R A F \mathrm{~V} 600 \mathrm{E}$ mutations were independent predictors for tumor prognosis, which is also in agreement with the literature (Costa et al., 2008; Henderson et al., 2009). As $B R A F$ gene mutations and lymph node metastasis are closely associated with tumor recurrence, pre-operative detection of the mutation and conventional lymph node dissection may help to reduce the recurrence rate (Bozec et al., 2011; Alzahrani and Xing, 2013).

Lower rates of the $B R A F$ V600E mutation have been discovered by direct DNA sequencing (Kebebew et al., 2007; Tufano et al., 2012). In the present study, a proportion of mutations detected by the multiplex allele-specific PCR and DHPLC assay showed only very low or even no mutation peak with DNA sequencing. Our method is therefore more appropriate for detecting low level mutations in fine-needle aspiration biopsy specimens. Due to the long storage time and paraffin-embedded conditions, DNA in some specimens might break into small fragments. Consequently, the mutant gene fragment may not be long enough for PCR detection, which can lead to false-negative results (Kebebew et al., 2007). In the present study, the fragment amplified by the multiplex allele-specific PCR only spanned $126 \mathrm{bp}$, and therefore has a wider range of applications. In the future, it would also be interesting to quantify the mutation with DHPLC and correlate the results with clinicopathological features of PTC.

In summary, we developed an efficient method for detecting the BRAF V600E mutation in PTC samples that is simple, rapid, sensitive, and of low cost. Our results also confirmed that this mutation is an independent predictor for PTC, which is closely associated with metastasis of central cervical lymph nodes. The next step will be to elucidate the concentration of the BRAF V600E mutation and biological behaviors of PTC, which will help to predict the degree of malignancy and aid decision-making for appropriate surgical treatment for the disease.

\section{ACKNOWLEDGMENTS}

Research supported by a grant from the Science and Technology Department of Sichuan Province (\#2011SZ0147).

\section{REFERENCES}

Alzahrani AS and Xing M (2013). Impact of lymph node metastases identified on central neck dissection (CND) on the recurrence of papillary thyroid cancer: potential role of BRAFV600E mutation in defining CND. Endocr. Relat. Cancer 20: 13-22. 
Bollag G, Tsai J, Zhang J, Zhang C, et al. (2012). Vemurafenib: the first drug approved for BRAF-mutant cancer. Nat. Rev. Drug Discov. 11: 873-886.

Bozec A, Dassonville O, Chamorey E, Poissonnet G, et al. (2011). Clinical impact of cervical lymph node involvement and central neck dissection in patients with papillary thyroid carcinoma: a retrospective analysis of 368 cases. Eur. Arch. Otorhinolaryngol. 268: 1205-1212.

Costa AM, Herrero A, Fresno MF, Heymann J, et al. (2008). BRAF mutation associated with other genetic events identifies a subset of aggressive papillary thyroid carcinoma. Clin. Endocrinol. 68: 618-634.

Davies H, Bignell GR, Cox C, Stephens P, et al. (2002). Mutations of the BRAF gene in human cancer. Nature 417: 949-954.

DeLuca AM, Srinivas A and Alani RM (2008). BRAF kinase in melanoma development and progression. Expert Rev. Mol. Med. 10: e6.

Gong RX, Zhou Y, Luo SH, Zhang L, et al. (2009). An investigation of BRAF mutation in papillary thyroid carcinoma and its clinical value. Zhonghua Yi Xue Yi Chuan Xue Za Zhi. 26: 310-313.

Henderson YC, Shellenberger TD, Williams MD, El-Naggar AK, et al. (2009). High rate of BRAF and RET/PTC dual mutations associated with recurrent papillary thyroid carcinoma. Clin. Cancer Res. 15: 485-491.

Howell GM, Carty SE, Armstrong MJ, Lebeau SO, et al. (2011). Both BRAF V600E mutation and older age ( $>/=65$ years) are associated with recurrent papillary thyroid cancer. Ann. Surg. Oncol. 18: 3566-3571.

Kebebew E, Weng J, Bauer J, Ranvier G, et al. (2007). The prevalence and prognostic value of BRAF mutation in thyroid cancer. Ann. Surg. 246: 466-470.

Kim TH, Park YJ, Lim JA, Ahn HY, et al. (2012). The association of the BRAF(V600E) mutation with prognostic factors and poor clinical outcome in papillary thyroid cancer: a meta-analysis. Cancer 118: 1764-1773.

Ries LAG, Melbert D, Krapcho M, Stinchcomb DG, et al. (2007). SEER Cancer Statistics Review, 1975-2005. National Cancer Institute, Bethesda. Available at [http:/seer.cancer.gov/csr/1975_2005/]. Accessed February 1, 2011.

Schlumberger M and Pacini F (2003). Prognostic Factors. In: Thyroid Tumors (Pacini F, ed.). Nucleon Editions, Paris, 111-125.

Tufano RP, Teixeira GV, Bishop J, Carson KA, et al. (2012). BRAF mutation in papillary thyroid cancer and its value in tailoring initial treatment: a systematic review and meta-analysis. Medicine 91: 274-286.

Witt RL (2008). Initial surgical management of thyroid cancer. Surg. Oncol. Clin. N. Am. 17: 71-91, viii.

Xing M (2005). BRAF mutation in thyroid cancer. Endocr. Relat. Cancer 12: 245-262.

Xing M, Clark D, Guan H, Ji M, et al. (2009). BRAF mutation testing of thyroid fine-needle aspiration biopsy specimens for preoperative risk stratification in papillary thyroid cancer. J. Clin. Oncol. 27: 2977-2982. 